\title{
HARDWARE DESIGN OF TWO WEIGHTED NEURAL NETWORK AND APPLICATION FOR OBJECT RECOGNITION
}

\author{
Wenming Cao, Fei Lu, Gang Xiao, Shoujue Wang \\ Institute of Intelligent Information System, ZheJiang University of Technology, Hangzhou \\ 310014, China
}

\begin{abstract}
In this paper, the design methodology of neural network hardware has been discussed, and two weighted neural network implemented by this method been applied for object recognition. It was pointed out that the main problem of the two weighted neural network hardware implementation lies in three aspects. At final, two weighted neural network implemented by this method is applied for object recognition, and the algorithm were presented. We did experiments on recognition of omnidirectionally oriented rigid objects on the same level, using the two weighted neural networks. Many animal and vehicle models (even with rather similar shapes) were recognized omnidirectionally thousands of times. For total 8800 tests, the correct recognition rate is $98.75 \%$, the error rate and the rejection rate are 0.5 and $1.25 \%$ respectively.
\end{abstract}

Key words: Pattern recognition, Two weighted Neural Networks, High dimensional Geometry

\section{INTRODUCTION}

As a suitable calculation method for parallel computing, the two weighted neural networks have been widely used in application for control theory1, speaker recognition2 etc. But how to realize the two weighted neural network computing, there are various methods such as realizing it by software or by full curing special neural network chip. The purpose of this paper is to research the application realized by semiconductor hardware and the process of enlarging the application. In section 2,we described its 
structure. In section 3, it was pointed out that the main problem of the two weighted neural network hardware implementation lies in three aspects. Finally, two weighted neural network implemented by this method is applied for object recognition, and the algorithm were presented. We did experiments on recognition of omnidirectionally oriented rigid objects on the same level, using the neural networks. Many animal and vehicle models (even with rather similar shapes) were recognized omnidirectionally thousands of times. For total 8800 tests, the correct recognition rate is $98.75 \%$, the error rate and the rejection rate are 0.5 and $1.25 \%$ respectively.

\section{STRUCTURE OF TWO WEIGHTED NEURAL NETWORKS}

The model is

$$
Y=f\left[\sum_{j=1}^{n}\left(\frac{W_{j}}{\left|W_{j}\right|}\right)^{s}\left|W_{j}\left(X_{j}-W_{j}^{\prime}\right)\right|^{P}-\theta\right]
$$

In which:

$\mathrm{Y}$ is the output of neuron;

$f(.$.$) is the neuron activation function;$

$X_{j}$ is neuron $\mathrm{jth}$ input;

$W_{j} W_{j}^{\prime}$ are direct weight and kernel weigh;

$\theta$ is the threshold;

$\mathrm{n}$ is the dimension of input.

We can easily get: if $S=1, P=1$ and all $W$ are zero, then the above equation becomes the traditional $\mathrm{BP}$ neuron; if $\mathrm{S}=0, \mathrm{P}=2$ and all the $\mathrm{W}$ are one, then the neuron becomes $R B F$ neuron; if $S=0$, change the value of $W$ and $P$, and if the basis of function $f(.$.$) is zero, the track of input X$ becomes the following closing hypersurfaces. Figure 1, ts topography structure Figure 2.
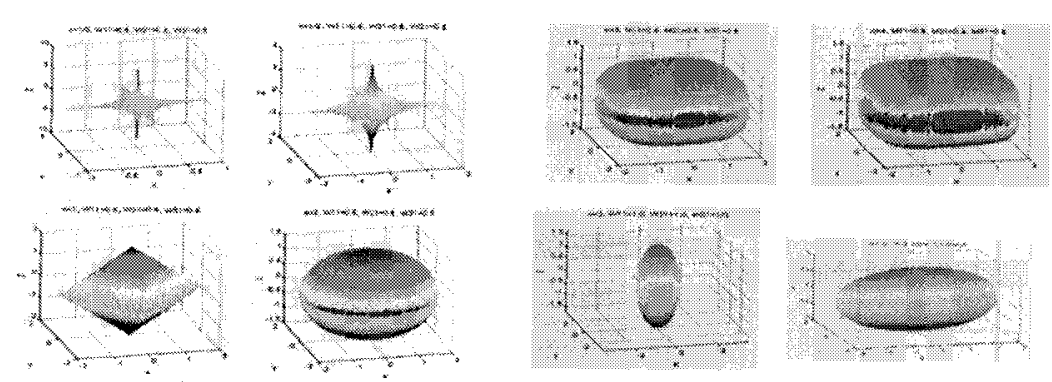

Figure 1. closing hypersurfaces 


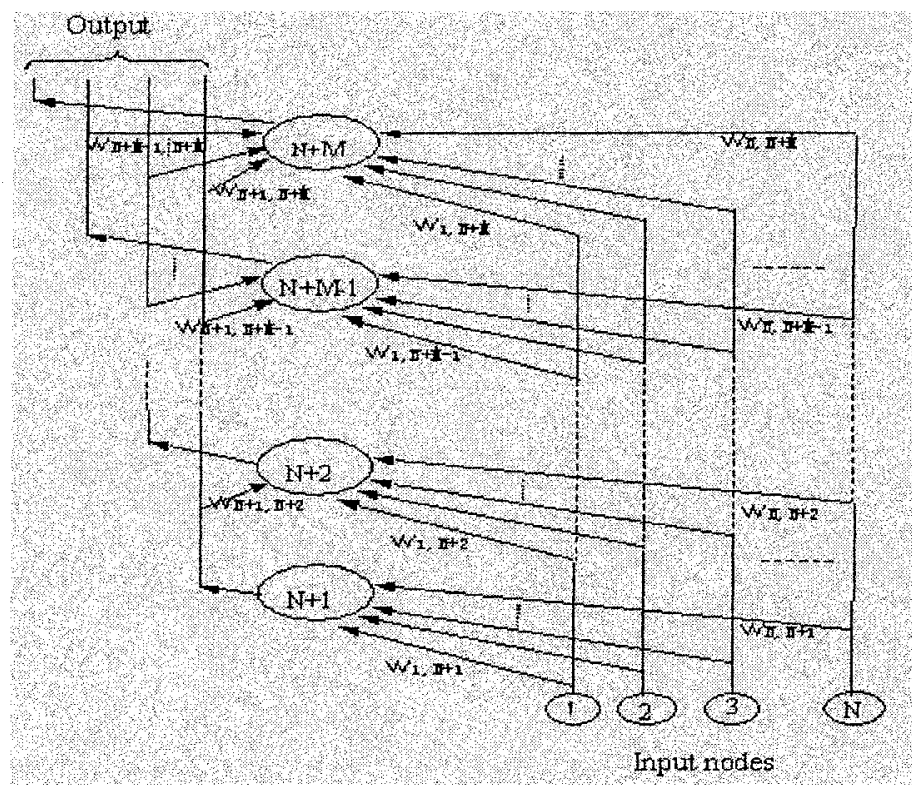

Figure 2. Structure of two weighted neural network

\section{ANALYSIS OF THE PROPERTY OF TWO WEIGHTED NEURAL NETWORKS HARDWARE}

Artificial two weighted neural networks are a computing method and device with a large number of computing units specially connected to form complex computing functions.

Let's take the currency degree for example: in scientific research, without the demand for particular use and structure, the two weighted neural networks generally need more powerful currency but the two weighted neural networks used for engineering need less powerful currency. However for those trained two weighted neural networks with fixed uses, (even the weights are fixed), there is no demand for currency. So we can divide all the demands into three fuzzy grades, that is high $(\mathrm{H})$, middle $(\mathrm{M})$ and low $(\mathrm{L})$. $(\mathrm{H})$ means the demand is high, that is to say: high computing speed or high precision or large net scale or strong flexibility or low price or easy to use or quantity. (L) However means the demand is lower and (M) means the demand is between the above two. For different purpose and different realization, we get the mapping relationship shown in figure by dividing all factors into three grades. 
As shown in table 1, we should select different approach for those two weighted neural networks with different demand. Improper approach may result the great inferior position on ratio of performance to price. A humor in Dan Hammerstrom[5] says: For a fully parallel network chip with $1 \mu \mathrm{m}$ interconnects and 109 connections, the spare of the connection is $89 \mathrm{~m}^{2}$.

\section{EXPERIMENT FOR OBJECT RECOGNITION}

By circling 8 animal and vehicle models (displayed in Fig.3) by 360 degrees respectively, each provides 400 samples. The whole of total 3200 samples of the 8 kinds is referred to the first sample set. Then, repeat the above process at a different time to get the second one. Finally, 2400 samples of another 6 animal models (displayed in Fig.4) are assembled in a similar way. The whole of the total 2400 samples is referred to the third sample set. The procedures and results of the experiment are labeled as follows:

According to the distance of samples of the same kind, select samples of each kind in inconsistent numbers ranging from 26 to 50 respectively from the total 3200 samples of the first sample set to compose a training set, which consequently consists of 328 samples from all 8 kinds.

Construct 8 recognition networks corresponding to the 8 models under recognition, where the number of neurons is equal to that of the samples in the training set.

Take the total 6400 samples of the first and second sample sets for correct recognition rate test. Consequently, 6384 samples were recognized successfully while the rest 16 ones failed. However, the rest 16 samples are totally attributed to the case of rejection. Therefore, the correct rate and rejection rate are $99.75 \%$ and $0.25 \%$ respectively.

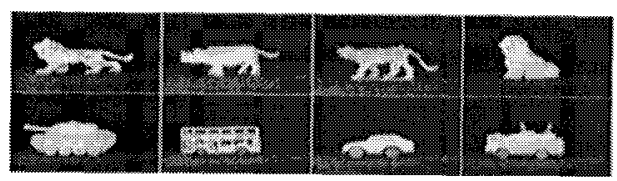

Figure 3. Testing Sample Set (1) 


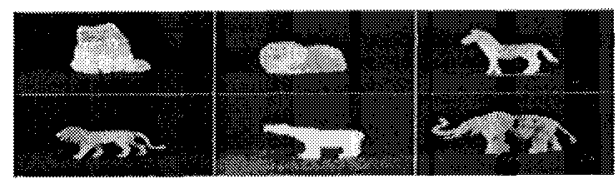

Figure 4. Training Sample Set (2)

\section{REFERENCES}

1.Wang ShouJue etc. "Discussion on the Basic Mathematical Models of Neurons in General Purpose Neurocomputer". ACTA ELECTRONICA SINICA, Vol.29 No.5, 2001

2.Wang Shoujue etc. The Sequential Learning Ahead Masking (SLAM) model of neural networks for pattern classification.Proceedings of JCIS98. Vol.IV. pp199-202. Oct. 1998. RTP. NC.. USA

3.Wang Shoujue. Priority Ordered Neural Networks with Better Similarity to Human knowledge Representation. Chinese Journal Of Electronics. Vol.8. No.1 ,pp. 1-4.1999,

4.Cao yu, Two weighted neural network approach, Master thesis, Institute of Semiconductors, CAS, 2002, 
Table 1. Two weighted Neurocompouter Chip

\begin{tabular}{|c|c|c|c|c|c|c|c|c|c|}
\hline \multirow{2}{*}{$\begin{array}{l}\text { Factors and } \\
\text { Requests }\end{array}$} & & \multicolumn{4}{|c|}{ Application } & \multicolumn{4}{|c|}{ Implement Approach } \\
\hline & & ST & $\mathrm{E}$ & $\mathrm{I}$ & SP & $S$ & $\begin{array}{l}\text { DSP } \\
\mathrm{A}\end{array}$ & $\begin{array}{l}\text { PS } \\
\text { TWNN }\end{array}$ & $\begin{array}{l}\text { OTON } \\
\mathrm{C}\end{array}$ \\
\hline $\begin{array}{l}\text { Computing } \\
\text { Speed }\end{array}$ & $\frac{\mathrm{H}}{\mathrm{M}}$ & H & L & $\mathrm{H}$ & $\mathrm{H}$ & L & $\mathrm{H}$ & $\mathrm{H}$ & $\mathrm{H}$ \\
\hline Accuracy & $\frac{\mathrm{H}}{\mathrm{M}}$ & $\mathrm{H}$ & M & $\mathrm{H}$ & M & $\mathrm{H}$ & $\mathrm{H}$ & $\mathrm{H}$ & $\mathrm{L}$ \\
\hline Net Scale & $\frac{\mathrm{H}}{\mathrm{M}}$ & $\mathrm{H}$ & M & $\mathbf{M}$ & M & $\mathrm{H}$ & $\mathrm{H}$ & $\mathrm{H}$ & L \\
\hline Flexibility & $\begin{array}{l}\frac{\mathrm{H}}{\mathrm{M}} \\
\mathrm{L}\end{array}$ & $\mathrm{H}$ & M & M & M & $\mathrm{H}$ & $\mathbf{H}$ & $\mathrm{H}$ & $\mathrm{L}$ \\
\hline Cost & \begin{tabular}{l|}
$\mathrm{H}$ \\
$\mathrm{M}$ \\
$\mathrm{L}$
\end{tabular} & L & $\mathrm{H}$ & M & $\mathrm{L}$ & $\mathrm{H}$ & $\mathrm{L}$ & M & $\mathrm{H}$ \\
\hline $\begin{array}{l}\text { Easy to } \\
\text { Use }\end{array}$ & $\frac{\mathrm{H}}{\mathrm{M}}$ & L & $\mathrm{L}$ & $\mathrm{H}$ & $\mathrm{H}$ & M & $\mathrm{L}$ & $\mathrm{H}$ & M \\
\hline Quality & \begin{tabular}{l|}
$\frac{\mathrm{H}}{\mathrm{M}}$ \\
$\mathrm{L}$
\end{tabular} & $\mathrm{L}$ & L & M & M & $\mathrm{M}$ & $\mathrm{L}$ & M & $\mathrm{H}$ \\
\hline
\end{tabular}

